\title{
Correlation between agrotechnical properties of selected soil types and corresponding GPR response
}

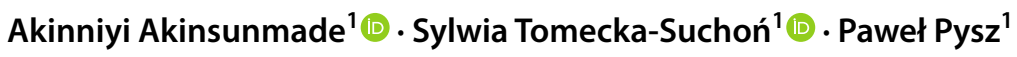

Received: 11 May 2019 / Accepted: 21 August 2019 / Published online: 3 September 2019

(C) The Author(s) 2019

\begin{abstract}
In this study, we investigated the relationship between ground-penetrating radar (GPR) response and agriculture properties of soil with a view to understanding how the constraint of soil degradation may influence the properties. GPR field data measurements were made at a location with soil types, properties, and disturbances caused by tractor movement. The data were processed, and empirical equations relating soil physical properties and material properties of soil media were considered for the analysis of the field data. The results showed a change in the reflection coefficient and increase in the GPR wave velocity when comparing the records of the initial parts of the GPR records, lasting about $2.5 \mathrm{~ns}$, of the signal response of soil subjected to compaction as a result of 10 tractor passes, with those obtained prior to movement of the tractor. The summation of the absolute value of GPR wave amplitude in the analyzed results clearly shows that the amplitude of the signal corresponding to the compressed ground is twice and even three times smaller than the amplitude recorded before the tractor runs. The results prompted the design of a relatively simple method for tracking changes in soil properties based on the results of GPR measurements, which show that zones subjected to direct tire pressure are easy to delineate and are not limited to the part that is directly under the tire, but extend about $0.5 \mathrm{~m}$. It thus shows that there is a relationship between the penetration resistance induced by a change in porosity and changes in the coefficient of reflectivity and the velocity of radar waves.
\end{abstract}

Keywords Soil · Physical properties · GPR · Reflection coefficient · Amplitude

\section{Soil properties}

Soil is a collection of living and non-living matter that forms a three-dimensional body (soil body) covering the surface of the earth. It begins where the atmosphere meets the soil surface and ends when bedrock or unweathered parent material is encountered. The formation of soil begins when a parent material encounters and interacts with the environment. The process involves weathering of the parent materials, which are primarily geologic bedrock. Subsequently, the bedrock erodes into smaller particles near the earth's surface; organic matter decays and mixes with inorganic material (rock fragments, soil minerals, water, and gases) to form soil.

Soil classifications vary throughout the world depending on the parameters that are used. However, the most widely

Akinniyi Akinsunmade

akinsunmade@agh.edu.pl

1 Faculty of Geology, Geophysics and Environmental Protection, AGH University of Science and Technology, Mickiewicza 30 Ave, 30-059 Krakow, Poland used are the World Reference Base for Soil Resources and the Soil Taxonomy developed by the United States Department of Agriculture (USDA). The latter is based on the profile characteristics of the soil and is preferred because it is based on soil properties that can be objectively observed or measured, rather than on presumed mechanisms of soil formation (Weil and Brady 2017).

Essentially, this classification system is based on the physical, chemical, and biological properties of the soil that are observable in the field or can be measured in the laboratory. In the context of this article, classification based on physical properties will be emphasized due to the focus of the research. From an agricultural point of view, the major physical properties used in soil classification are color, texture, structure and bulk density, porosity, consistency, temperature, and air content. All of these are interrelated and influence other physical quantities such as water saturation and degree of compaction, which may be evaluated empirically. Air is retained in soil micropores, and its composition varies; it contains higher carbon dioxide and moisture and 
lower oxygen concentrations than atmospheric air (Osman 2012).

The most dependable and basic classification of soil is based on physical properties and texture, which define the particles that make up the soil. This is because the texture of soil in the field is rarely subject to change, and so it is considered a basic permanent property. A fundamental understanding of the amount of the different-sized particles is germane to the comprehension of soil behavior, management, and characterization. The variable particle sizes enable the grouping of soil particles into different types, including sand, silt, and clay, based on the diameter of the individual particles. Sand particles range in size from 0.005 to $2 \mathrm{~mm}$ and are composed mainly of quartz, so sandy soils contain few plant nutrients. The large pores cannot hold water against the pull of gravity, which gives it little capacity to retain water or nutrients. Silt, on the other hand, is smaller, $0.002-0.05 \mathrm{~mm}$ in diameter. The pores between particles are smaller than those of sand and as such can retain water. The soil type with the smallest particles is clay, with a diameter of $<0.002 \mathrm{~mm}$. As a result, it has a larger surface area and higher capacity to absorb water and other substances. The combination of these three soil types leads to a fourth classification, called loam. Loam contains varying amounts of sand, silt, and clay. Sandy, silty, and clayey soil and loam are all usable for agricultural activity, particularly for plant growth. However, most soils are composed of a combination of the different types. Their mixture will determine the texture of the soil, or in other words how the soil looks and feels. Various soils are found at different horizons near the earth's.

Soil must be able to provide for a system to transport water, air, and minerals to the roots of plants. Such a system consists in infiltrating water into deeper soil layers, from which all necessary capillary properties components are carried into the plant's root system. Infiltration into the ground requires the existence of relatively large pores connected to each other to ensure efficient water drainage. On the other hand, components with smaller granulation allow building a capillary transport system essential in the proper nutrition of plants. Accordingly, recognizing the distribution of porosity of the ground (which is directly associated with the volumetric water content) and distribution of soil compaction is a vast problem for achieving optimal yields.

\section{Electrical properties of soil}

It should be noted that changes in the agrotechnical properties of soil are closely related to the volume fraction of water in the soil structure or its mineralization. This relationship may be the basis for the use of ground-penetrating radar (GPR) to study the quality of agricultural soils, in particular, changes in soil properties as a result of agrotechnical or anthropogenic environmental changes. Kielbasa et al. (2011) evaluated the link between agrotechnical and operational factors in relation to the size and quality of potato yields.

Electrical permittivity $(\varepsilon)$ of a medium composed of various components has been widely described mathematically in the literature (Schon 1996; Carcione and Schoenberg 2000; Marcak and Tomecka-Suchoń 2009). For a suitably selected frequency band, the electrical permeability determined from radar measurements is proportional to static electrical permittivity $\left(\varepsilon_{\mathrm{s}}\right)$. Because of the generally high value of $\varepsilon_{\mathrm{s}}$ for water, its role in the formula is decisive, and changes in the volume of water (that is, soil water saturation) and the value of water permittivity fully approximate the changes in ground electrical permittivity (Marcak and Tomecka-Suchon 2009). In addition to water saturation, the electrical conductivity of water plays an important role in the response of the ground to distortion in the form of passing radar waves (Marcak and Tomecka-Suchoń 2009).

The solution of the electromagnetic waves propagating directly downward along the $z$ axis has the form:

$E_{y}=B e^{i(\omega t-a z)-b z}$

where $E_{y}$ is the component of the electrical field in the $y$ direction, $\omega$ is frequency, and $B$ is a constant.

The coefficient $b$ is to some extent a measure of water mineralization (Marcak and Tomecka-Suchoń 2009). Both parameters $\gamma$ (electrical conductivity) and the damping factor $b$ are associated with water saturation and given by the formula:

$b=\frac{\omega \sqrt{\varepsilon}}{\sqrt{2}} \sqrt{\sqrt{1+\left(\frac{\gamma}{\varepsilon \cdot \omega}\right)^{2}-1}}$

Parameter $a$ is related to the wave phase velocity $(V)$ :

$V=\frac{\omega}{a}$

and has the form:

$a=\frac{\omega \sqrt{\varepsilon}}{\sqrt{2}} \sqrt{\sqrt{1+\left(\frac{\gamma}{\varepsilon \cdot \omega}\right)^{2}+1}}$

For perpendicular polarization of an electrical field to the earth's surface, the radar observation, the reflection coefficient $(R)$ and coefficient of transmission $(T)$ have the forms:

$$
\begin{aligned}
& R=\frac{a_{1}-a_{2}}{a_{1}+a_{2}} \\
& T=\frac{2 a_{1}}{a_{1}+a_{2}}
\end{aligned}
$$


Changes in the agricultural properties of soil that adversely affect plant growth, such as changes in the distribution of pores caused by soil loading by agricultural machines, the occurrence of large solid rock inclusions, or disturbance in groundwater levels, can be identified by GPR methods and can be recognized by changes in $V, R$, and $T$ parameters. Using the GPR method, it is also possible to identify changes in groundwater mineralization resulting from the impact of landfills of various types of waste near cultivated agricultural fields by analysis of the $b$ parameter in Eq. 2.

Commonly used methods to estimate porosity and compaction are based on laboratory tests and penetrometer (PR) measurements, which are time-consuming and provide sparse information. The GPR method is noninvasive and rapid, and provides very dense information about the electrical features of the soil.

Romero-Ruiz et al. (2019) suggested a number of ways to circumvent the limitations of conventional methods of soil characterization via the use of various geophysical methods which improve the objectivity of soil characterization. A study by Plati and Loizos (2013) reported the use of trace reflection amplitude for investigating in situ density and moisture content within a pavement section of a road. A comparison of laboratory and GPR measurement results of sandy soil was conducted by Ercoli et al. (2018).

Geophysical characterization of a river bed was performed by Brito et al. (2018), who recorded the changes in water content, granularity, sediment type, layer orientation, and water table zone. The use of GPR for sensing soil physical characteristics and crop root measurement was reviewed by Liu et al. (2016), who found that GPR was a superior non-destructive method compared with other methods of soil investigation. Muñiz et al. (2016) evaluated a grazing field with significant compaction within $24 \mathrm{~cm}$ of the soil surface in comparison with a non-grazing field, and Jonard et al. (2013) characterized the effects of soil tillage using GPR and electromagnetic induction. Raper et al. (1990) performed a hardpan experiment on soil at different depths and bulk density, and subsequently carried out an investigation using GPR and a penetrometer. The use of GPR waves on the reflecting border as against the classical method of interpretation was documented by Marcak and Tomecka-Suchoń (2010), who demonstrated the use of phase changes in reflected GPR waves for interpreting the impact of mining waste deposits on soil water contamination. Their findings proved the efficiency of the techniques. Unfortunately, correlations between the physical properties and the reflectivity coefficient of the media are generally lacking in the literature.

\section{Use of GPR method for assessing the effects of soil compaction}

Soil compaction has become a significant problem in agriculture practices worldwide. Heavy machinery used in intensive farming produces compaction as a result of the heavy weight on the tires. Soil grains are rearranged, leading to reduced void space and increased bulk density. Compaction restricts plant root growth, as the large reduction in pore space within the macropores as a result of compaction causes mechanical resistance and decreases the supply of oxygen (Unger and Kaspar 1994). This phenomenon is also a subject of scientific research. Repeated wheeling by tractors limit soil aeration (Czyż 2004).

Penetration resistance (PR) is used in science for describing the level of soil compaction. Plant root growth can be related to the PR and is reduced by $50 \%$ for PR between 2.0 and 3.0 MPa, and generally stops when PR is greater than 3.0 (Bengough and Mullins 1990).

A model used for PR assessment can be expressed by the following formula (da Silva and Kay 2004):

$\mathrm{PR}=a \theta^{b} D^{c}$

where $\theta$ is water content, $D$ is bulk density, and $a, b$, and $c$ are constants.

The relationship between $\theta$ and water potential $\psi$ (Leo et al. 2006) has the form:

$\theta=e^{d+e D} \psi^{l}$

where $d, e$, and $l$ are constants.

These two equations enable the establishment of a direct relation between $\mathrm{PR}$ and $\theta$ :

$\ln (\mathrm{PR})=\ln (a)+b \cdot \ln (\theta)+c \cdot \ln \left(\frac{\ln (\theta)-l \cdot \ln (\psi)-d}{e}\right)$

According to Eqs. 8 and 9, this means that the changes in PR cause changes in the coefficient of reflectivity and the velocity of electromagnetic waves.

In this study, an attempt is made to establish the relationship between the measured or evaluated soil physical properties and the ground penetrating radar (GPR) signal responses, with a view to better understanding the constraint any degradation of the soil may have on the soil's properties. The focus also includes determination of the physical properties that most influence the electromagnetic pulse energy of a GPR system. 


\section{Method of research}

\section{Field data measurement}

In the field, measurements were made on soil used for cultivation of crops in part of Krakow, Poland, with compaction induced by the movement of tractors to simulate farming activity. The average weight of the tractor used to induce the soil compaction was $16,000 \mathrm{~kg}$, while the inflation pressure of the front and rear tires was $1.5 \mathrm{~kg} / \mathrm{cm}^{2}$ and $2.5 \mathrm{~kg} / \mathrm{cm}^{2}$, respectively. The soil was predominantly sandy loam soil for growing of crops. Loam is soil composed mostly of sand and silt and a smaller amount of clay. By weight, its mineral composition is about 40-40-20\% sand-silt-clay, respectively. These proportions can vary to a degree, however, and result in different types of loam soils: sandy loam, silty loam, clay loam, sandy clay loam, silty clay loam, and loam (Kaufmann and Cleveland 2008). Loam soils generally contain more nutrients, moisture, and humus than sandy soils, have better drainage and infiltration of water and air than silt and clay-rich soils, and are easier to till than clay soils. The soil's texture, especially its ability to retain nutrients and water, is crucial (Brown 2007). All of these characteristics make loam soil useful for agricultural purposes, which informed the choice of the location for the study. GPR data were acquired using a MALA RAMAC GPR system with a shielded antenna system of central frequency of $800 \mathrm{MHz}$ (Fig. 1). The choice of the antenna was based on target depth and resolution. Data collection was done in the both wide- and short-offset mode (Fig. 1). A total of 14 profiles were acquired. Three of the profiles have length of about $70 \mathrm{~m}$, while the remaining profiles were $10 \mathrm{~m}$ long and perpendicular to the three profiles (Fig. 2).

The GPR systems were set up and mounted, and data were collected by pulling the wheeled antenna along the profile lines at walking speed. The system generates radar pulses at a given central frequency. In this study, an $800-\mathrm{MHz}$ signal was sent into the earth through a transmitting antenna. The pulses are scattered back at electromagnetic discontinuities of the subsurface, mainly due to contrast in dielectric constant between soil and buried objects or different layers. The back-scattered pulses are collected by a receiving antenna, and the data are presented as signal amplitudes versus travel time in the form of an image (radargrams, Fig. 3).

\section{Data processing}

Human error, equipment, and environmental artifacts may be unknowingly introduced into measured field data. Of course, this may result in misinformation at the interpretation stage. To ameliorate this, it is important that the field data are subjected to processing. Generally, to improve the signal-tonoise ratio (SNR), the measured data were scrutinized. This was made possible using Reflexw software developed by Sandmeier Consulting, Germany (Sandmeier 2012). The Reflexw software made it easier to remove low frequencies from the data through the "dewow" tool. To resolve all traces to a common zero point, the time zero correction tool was activated on all the data sets to bring them to a fixed starting time. The background removal tool was further activated in
Fig. 1 Wide-offset and shortoffset field measurements
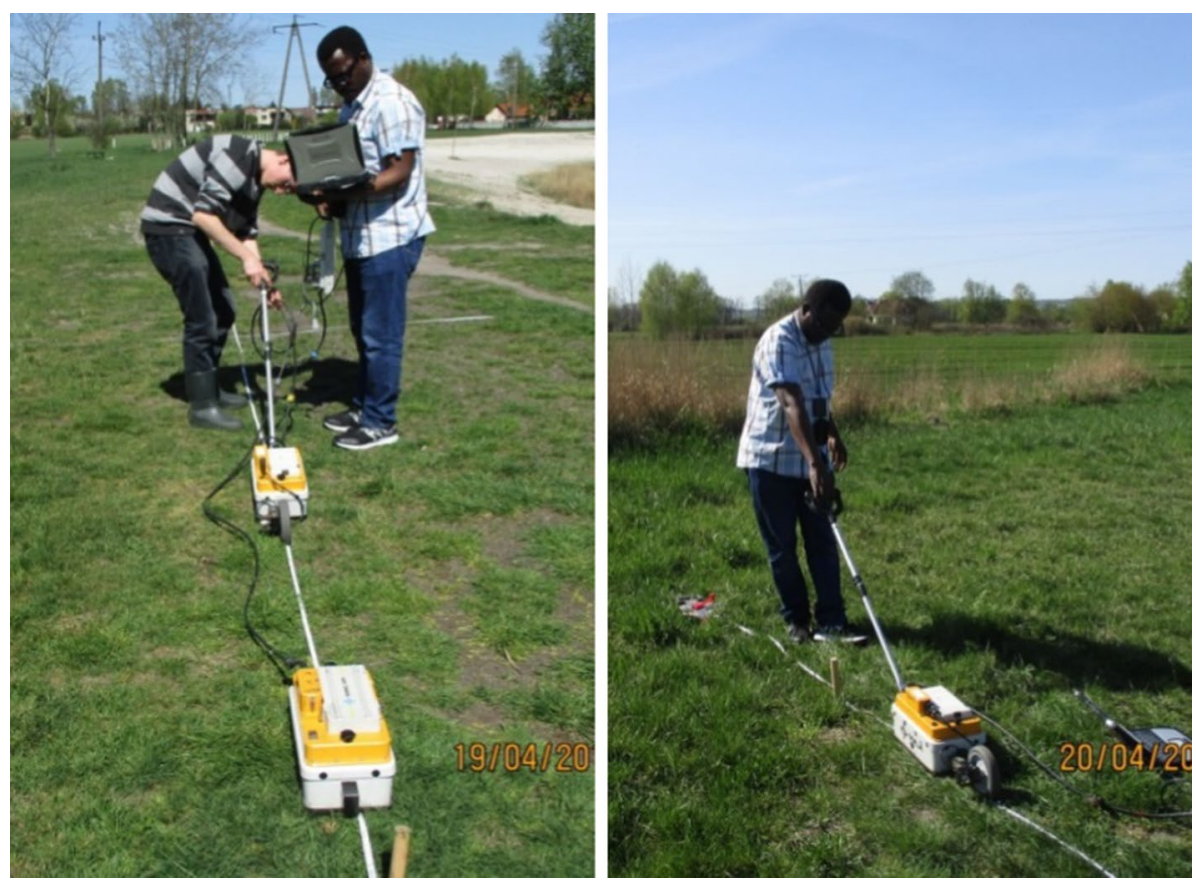
Fig. 2 Field data measurement site with profile (red lines) layouts and compaction zones induced by tractor tires
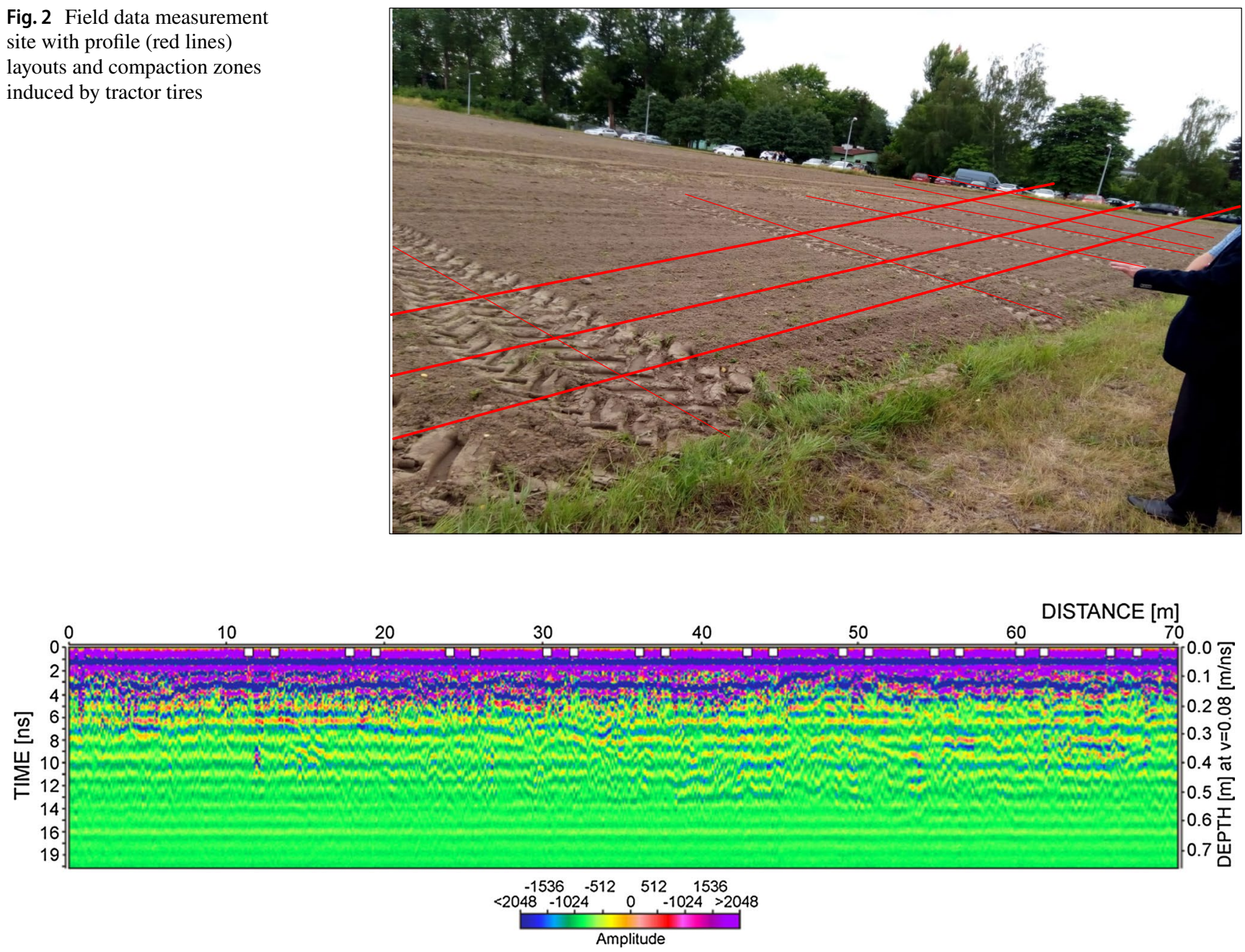

Fig. 3 Radargram of a profile in one of the field measurement plots

the third step to temporarily remove coherent noise from the processed data. In order to enhance the signals received from the deeper depths, the gain tool was applied to enhance the drastic fall in energy of the wave before reaching the receiver. Subsequent to the processing, moving-average calculations were performed on the data which have been hitherto converted into the matrices form. The essence of this operation is to remove effects of random noise that may obliterate the targeted response, which may hamper optimal interpretation.

\section{Results and discussion}

In accordance with the considerations made in the previous paragraphs, the effects of compaction in the soil should cause a reduction or disappearance of large pores in soil, and as a consequence, a reduction in the volume of water in the soil structure. Such a change should result in a change in the reflection coefficient and an increase in GPR wave velocity. This effect is discernable by comparing the records of the initial parts of the GPR records, lasting about $2.5 \mathrm{~ns}$, of the signal response carried out over ground subjected to compaction as a result of 10 tractor passes and signal response obtained prior to the impact of the tractor tire. The plot of the analysis is shown on Fig. 4a, b.

The summing results clearly show that the amplitude of the records corresponding to the compressed ground is twice (the right wheel) and even three times (the left wheel) smaller in comparison with the amplitude recorded before the tractor runs. The change in the amount of water in the porous parts of the ground caused a marked reduction in the intensity of the reflected and scattered wave in the initial parts of the records. In the records corresponding to the left tire, the change in the velocity of GPR propagation can easily be seen. These results prompted us to design a relatively simple method of tracking changes in land properties from the results of GPR measurements (Fig. 5). 

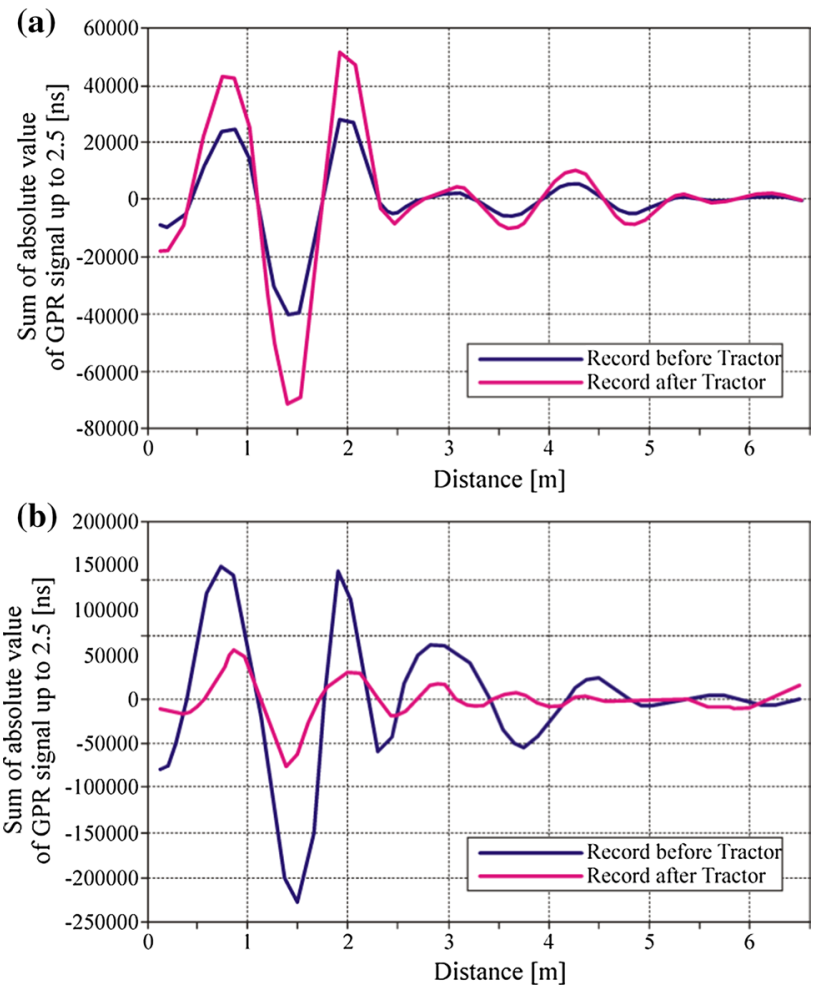

Fig. 4 Summary of GPR amplitudes recorded on paths located over the ground subjected to compaction by the tractor tire after 10 tractor passes. The recording length is $2.5 \mathrm{~ns}$. Series 1 records after the tractor runs, and series 2 records before the tractor runs: a right wheel; $\mathbf{b}$ left wheel

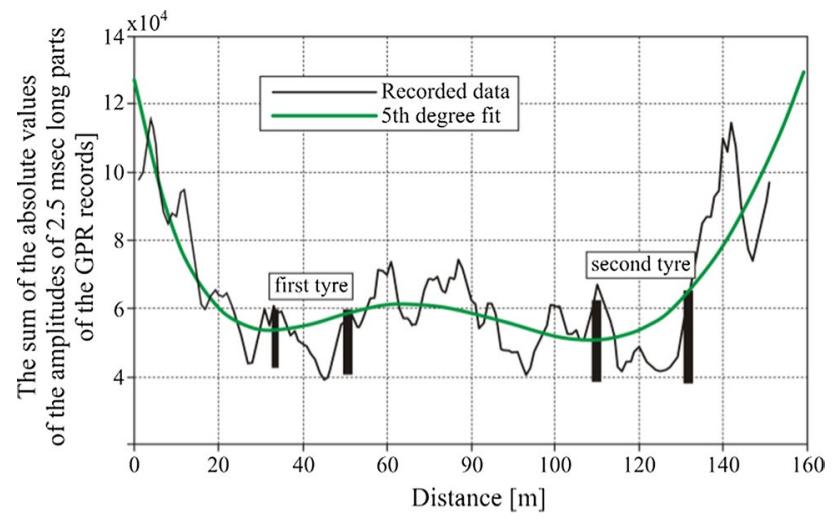

Fig. 5 A graph of the sum of the absolute values of the amplitudes of 2.5-ns-long parts of the GPR records obtained along the profile perpendicular to the tractor's route. The results are approximated by a fifth-degree polynomial fit

Figure 5 shows a graph of the sum of the absolute values of the initial amplitudes of 2.5-ns-long parts of GPR records obtained along the profile perpendicular to the tractor's route. It is clear that zones subjected to direct tire pressure are easy to determine; at the same time, it can be seen that the tractor's action is not limited to only the part that is directly under the tire, but has a wider character and influence distance in the range of $0.5 \mathrm{~m}$.

\section{Conclusions}

Results of the analysis of GPR data in this study have depicted that the most important element influencing GPR wave transmission is dielectric permittivity. Water has a relative dielectric permittivity value of 81 , compared with values of 1 and 3-5 for air and unsaturated soil, respectively. It is obvious that the water content of soil with its quality must be related to the changes in parameters of the GPR waves such as velocity, attenuation, coefficient of reflectivity, intensity of transmitted waves, and angle of reflection.

From an agricultural point of view, strong compaction reduces macropores within the soil matrix and hence reduces water content, which causes degradation to soil, impeding optimal utilization by crops. The experiment with varying numbers of tractor passes resulted in the creation of compacted soil. GPR measurements along the tractor zones proved that there was a significant change at the beginning of radar traces. Evaluation of some of the absolute values of amplitude at $2.5 \mathrm{~ns}$ gives an accurate position response to external influences such as vertical impact as in the case of tractor passes.

This experiment allows us to propose a rather simple method for quick interpretation of the location of compacted soil with the GPR method. Losses in crop production that may be related to poor growth of plants as a result of soil degradation due to compaction can be swiftly investigated by GPR using this technique. Finally, this GPR data interpretation approach may be extended to the study of changes in soil structure, soil water content, and soil contamination.

Acknowledgements This paper was financially supported through research subsidy no. 16.16.140.315 at the Faculty of Geology Geophysics and Environmental Protection of the AGH University of Science and Technology, Krakow, Poland, 2019. The paper was presented at the CAGG 2019 Conference "Challenges in Applied Geology and Geophysics" organized at the AGH University of Science and Technology, Krakow, Poland, 10-13 September 2019. The authors sincerely appreciate the assistance from Henryk Polański and Jerzy Karczewski during field measurements. In addition, we would like to thank Tadeusz Juliszewski for preparation of the test field.

\section{Compliance with ethical standards}

Conflict of interest On behalf of all authors, the corresponding author states that there is no conflict of interest. 
Open Access This article is distributed under the terms of the Creative Commons Attribution 4.0 International License (http://creativeco mmons.org/licenses/by/4.0/), which permits unrestricted use, distribution, and reproduction in any medium, provided you give appropriate credit to the original author(s) and the source, provide a link to the Creative Commons license, and indicate if changes were made.

\section{References}

Bengough AG, Mullins CE (1990) Mechanical impedance to root growth: a review of experimental techniques and root growth responses. J Soil Sci 41(3):341-358. https://doi. org/10.1111/j.1365-2389.1990.tb00070.x

Brito GLM, Coutinho AP, Cabral JJDSP et al (2018) Characterization of the Capibaribe River dry bed with ground penetrating radar (GPR). RBRH. https://doi.org/10.1590/2318-0331.0318170023

Brown RB (2007) Soil texture: soil and water science Department. Florida Cooperative Extension Service, Institute of Food and Agricultural Sciences, University of Florida, Gainesville, FL, pp $32-611$

Carcione JM, Schoenberg MA (2000) 3-D ground-penetrating radar simulation and plane-wave theory in anisotropic media. Geophysics 65(5):1527-1541. https://doi.org/10.1190/1.1444841

Czyż EA (2004) Effects of traffic on soil aeration, bulk density and growth of spring barley. Soil Tillage Res 79(2):153-166. https:// doi.org/10.1016/j.still.2004.07.004

Da Silva AP, Kay BD (2004) Linking process capability analysis and least limiting water range for assessing soil physical quality. Soil Tillage Res 79(2):167-174. https://doi.org/10.1016/j.still .2004.07.005

Ercoli M, Di Matteo L, Pauselli C et al (2018) Integrated GPR and laboratory water content measures of sandy soils: from laboratory to field scale. Constr Build Mater 159:734-744. https://doi. org/10.1016/j.conbuildmat.2017.11.082

Jonard F, Mahmoudzadeh M, Roisin C et al (2013) Characterization of tillage effects on the spatial variation of soil properties using ground-penetrating radar and electromagnetic induction. Geoderma 207:310-322. https://doi.org/10.1016/j.geode rma.2013.05.024

Kaufmann RK, Cleveland CJ (2008) Environmental science. McGrawHill College, McGraw-Hill, pp 318-319

Kiełbasa P (2011) Integrated method of energy expenditure assessment for basic cultivation in the aspect of soil mosaic. Agric Eng $15: 1-137$
Leo TP, de Silva AP, Macedo MCM, Imhoffs S, Euclides VPB (2006) Least limiting water range a potential range a potential indicator of changes in near-surface soil physical quality after the conversion of Brazilian Savanna into pasture. Soil Tillage Res 88:279-285. https://doi.org/10.1016/j.still.2005.06.014

Liu X, Dong X, Leskovar DI (2016) Ground penetrating radar for underground sensing in agriculture: a review. Int Agrophys 30:533-543. https://doi.org/10.1515/intag-2016-0010

Marcak H, Tomecka-Suchoń S (2009) The GPR measurements for assessment a mineralization of the soil water. Geologia 35:445454 (in polish)

Marcak H, Tomecka-Suchoń S (2010) Properties of georadar signals used for an estimation of the mineralization of the soil waters. Arch Min Sci 55:469-486

Muñiz E, Shaw RK, Gimenez D, Williams CA, Kenny L (2016) Use of ground-penetrating radar to determine depth to compacted layer in soils under pasture. In: Minasny B, Hartemink A (eds) Digital soil morphometrics. Progress in soil science. Springer, Cham, pp 411-421. https://doi.org/10.1007/978-3-319-28295-4_26

Osman KT (2012) Soils: principles, properties and management. Springer, Berlin

Plati C, Loizos A (2013) Estimation of in situ density and moisture content in HMA Pavements based on GPR trace reflection amplitude using different frequencies. J Appl Geophys 97:3-13. https ://doi.org/10.1016/j.jappgeo.2013.04.007

Raper RL, Asmussen LE, Powell JB (1990) Sensing hard pan depth with ground-penetrating radar. Trans ASAE 33:41-46. https://doi. org/10.13031/2013.31291

Romero-Ruiz A, Linde N, Keller N, Or D (2019) A review of geophysical methods for soil structure characterization. Rev Geophys 56:672-697. https://doi.org/10.1029/2018RG000611

Sandmeier KJ (2012) REFLEXW Version 7.0 Windows ${ }^{\mathrm{TM}} 9 \mathrm{x} /$ NT/2000/XP/7-program for the processing of seismic, acoustic or electromagnetic reflection and transmission data

Schon JH (1996) Physical properties of rocks: fundamentals and principles of petrophysics. Pergamon, New York

Unger PW, Kaspar TC (1994) Soil compaction and root growth: a review. Agron J 86:759-766. https://doi.org/10.2134/agronj1994 $.00021962008600050004 \mathrm{x}$

Weil RR, Brady NC (2017) The nature and properties of soils. Pearson, London 